\title{
Clown- o palhaço como intervenção e humanização em saúde
}

\section{The clown as intervention and health humanization}

\author{
Cristiane Pavanello Rodrigues Silva ${ }^{1}$ (orcid.org/0000-0001-9298-2950), Ana Paula da Conceição ${ }^{1}$, Ana Paula dos Santos \\ Chagas $^{2}$ \\ 1. Escola Superior de Saúde de Santa Maria (ESSSM), Porto, Portugal. 2. Universidade Paulista (UNIP), Tatuapé, SP, Brasil.
}

\begin{abstract}
Resumo
Introdução: A humanização na saúde é uma relação efetiva de cuidados, que se evidenciam na acolhida, na sensibilidade, no respeito e na compreensão do doente e não somente da doença. Ressalta-se a importância do voluntariado nas organizações, cujo trabalho pode beneficiar a transformação do ambiente na direção da humanização. Objetivo: descrever a percepção dos participantes do grupo de voluntários "Doutoralhaços" com o trabalho de Clown como intervenção na saúde. Métodos: Pesquisa qualitativa, de campo, com análise de conteúdo, em São Paulo, amostra de 13 participantes. Foi aplicado instrumento específico: dados sociodemográficos e questionário aberto, estruturado, para avaliação da percepção dos voluntários. Resultados: Houve $56,5 \%$ de adesão, com 100\% de percepção "satisfatória" com o trabalho do grupo com ênfase na humanização e na integração; 33\% citaram a percepção da melhora na resposta ao tratamento, $61,5 \%$ referiram não ter dificuldades relacionadas aos profissionais de saúde, com boa receptividade, ênfase na importância da humanização, presente no trabalho voluntário; ficou evidente o reconhecimento do grupo perante os profissionais; $11,8 \%$ dos participantes relataram a necessidade de atenção e humanização, também, para os familiares e profissionais da saúde, de forma lúdica, com redução do foco no estresse da dor e da doença. Conclusão: a humanização é ponto chave do bem-estar do paciente, um olhar holístico para além da doença, para um ser biopsicossocial e espiritual. A intervenção de saúde, por meio do Clown, é factível no ambiente hospitalar à medida que permite humanizar e estimular a recuperação do ser humano de forma ampla e integrada.
\end{abstract}

Palavras-chave: Humanização da Assistência. Voluntários. Clown.

\begin{abstract}
Introduction: Humanization in health is an effective relationship of care, evidenced in the acceptance, sensitivity, respect and understanding of the patient and not only in terms of the disease. Emphasis is given to the importance of volunteering in organizations, whose work can benefit the transformation of the environment towards humanization. Objective: to describe the perception of the participants of the group of volunteers "Doutoralhaços" acting as clowns as an intervention in health. Methods: Qualitative field research, with content analysis, in São Paulo, sample of 13 participants. A specific instrument was applied: sociodemographic data and an open structured questionnaire to assess the perception of volunteers. Results: There was $56.5 \%$ adherence, with 100\% "satisfactory" perception of the group's work with emphasis on humanization and integration; 33\% cited the perception of improvement in the response to treatment, $61.5 \%$ reported not having difficulties related to health professionals, with good receptivity, emphasis on the importance of humanization, present in voluntary work. The group's recognition of the professionals was evident; $11.8 \%$ of the participants reported the need for attention and humanization, in a playful way, to the relatives and health professionals, with a reduced focus on the stress of pain and illness. Conclusion: that humanization is a key point for patient well-being, a holistic look beyond disease, toward a biopsychosocial and spiritual being. The health intervention, by means of the Clown, is feasible in the hospital environment as it allows humanizing and stimulating recovery of the human being in a broad and integrated way.
\end{abstract}

Key words: Humanization of Assistence. Volunteers. Clown

\section{INTRODUÇÃO}

A humanização do cuidado em saúde compreende, antes de tudo, uma relação efetiva de cuidado, o qual pode evidenciarse na acolhida, na sensibilidade, no respeito e na compreensão do indivíduo e não somente da doença. Refere-se, também, a reduzir ao mínimo a interrupção entre a vida normal do paciente e a que lhe impõe restrições, no sentido de respeitar ao máximo o comportamento que ele tinha antes da internação. O paciente e sua família precisam ser acolhidos e compreendidos a partir de sua história pessoal e social, seus valores, suas crenças e seus sentimentos, o que significa tornar a permanência do paciente no hospital a menos traumática possível, uma vez que o hospital, por si só, muitas vezes, representa dor, sofrimento e perdas ${ }^{1}$.

É necessário compreender a razão da proposta de humanização, que significa não somente competências técnicas do profissional, mas também a capacidade de compreender o paciente enquanto ser humano, seus valores, suas crenças, seus desejos e suas perspectivas. Implica o sentido de mudança, pois, a construção de um novo quadro ético de referências para as relações, as diferenças entre os seres humanos, não impõe necessariamente desigualdade de poder, mas o resultado de relações decorrentes de experiências vividas com outras pessoas ${ }^{1}$. 
No Brasil, no ano 2000, o Ministério de Saúde regulamentou o Programa Nacional de Humanização da Assistência Hospitalar (PNHAH), que estabelece uma política pública que se destina a promover uma nova cultura de atendimento à saúde, com o objetivo de aprimorar as relações entre profissionais, entre paciente e profissional e entre hospital e comunidade, visando à melhoria da qualidade e à eficácia dos serviços prestados por estas instituições².

Para o desenvolvimento do processo de humanização hospitalar, um dos mecanismos importantes é a criação e inserção de grupos de trabalho de humanização, que tenham como objetivo envolver os vários fatores da instituição na modificação da cultura institucional hospitalar, tornando-a mais humanizada ${ }^{2,3}$. Dessa forma, no processo de humanização, sabe-se que os voluntários desempenham importante papel, no sentido de promover a participação do paciente e dos profissionais, não somente em rotinas hospitalares, mas em recreações, conversas, entre outros métodos de humanizar, a fim de estabelecer um vínculo em uma visão mais ampla, tentando diminuir o foco apenas na doença ${ }^{4}$.

A humanização do ambiente hospitalar, por meio da utilização de brincadeiras em enfermarias, é um tema que vem sendo estudado na área da Psicologia Hospitalar. Esta atividade lúdica é "sempre terapêutica e saudável, sendo uma forma de descarregar a agressividade e reconhecer o mundo"; além de ser uma forma de comunicação em psicoterapia entre paciente, voluntários e profissionais, conduz a relacionamentos grupais, facilitando o desenvolvimento e melhoria do bem-estar ${ }^{5}$.

No Brasil, há um grupo pioneiro em levar a "brincadeira" para dentro dos hospitais: os "Doutores da Alegria". Essa experiência se valeu dos recursos do palhaço: o jogo, o olhar, a escuta, o aprendizado mútuo - para atuar na formação de públicos diversos em todo o território nacional, desde voluntários a profissionais que queiram exercitar a criatividade. A missão dos "Doutores da Alegria" é promover a experiência da alegria como "fator potencializador" de relações saudáveis por meio da atuação profissional de palhaços junto a pacientes hospitalizados e profissionais de saúde; é também compartilhar a qualidade desse encontro da sociedade com a produção de conhecimento, formação e criações artísticas ${ }^{6}$.

O termo clown (palavra da língua inglesa que significa "palhaço") é usualmente utilizado, no Brasil, para designar a atuação desse personagem em espaços não circenses, como o teatro e o hospital. Uma das explicações está ligada à necessidade de diferenciar o trabalho do palhaço no picadeiro e em outros palcos. No picadeiro, ele tem os gestos adequados para a área grande e a plateia numerosa, com movimentos amplos, voz projetada e maquiagem carregada, em função da amplitude. Em contraste, o trabalho no hospital envolve outras características: a plateia muitas vezes se resume a uma pessoa, em uma condição debilitada e em um ambiente que, muitas vezes, é "amedrontador"7.

Outro motivo para o uso do termo clown está ligado à própria proposta de trabalho dos palhaços de hospitais como os "Doutores da Alegria" e outros grupos semelhantes como os "Doutoralhaços". Há mais de vinte anos, quando os "Doutores da Alegria" começaram, existia um grande desconhecimento ou uma compreensão pejorativa sobre o papel do palhaço. Chamar alguém de palhaço era uma forma de depreciação ou ofensa. Sua figura, como animador de festas e eventos, muitas vezes remetia a um caráter patético ou distante do que é a essência de sua atuação ${ }^{6}$.

Ao longo do tempo, porém, houve uma grande mudança nesses padrões. Desenvolveram-se programas para formação na arte de ser palhaço, ao mesmo tempo em que o sucesso do trabalho dos "Doutores da Alegria" também ajudou a resgatar a nobreza do termo palhaço. Embora ainda se use a palavra clown, é importante esse trabalho de resgate; afinal, as crianças hospitalizadas esperam pelos palhaços. É assim que se referem a eles ${ }^{7}$.

Desde a criação dos Doutores da Alegria, observa-se o surgimento de um grande número de iniciativas que incluem a atuação de palhaços em hospitais, em diferentes regiões do país e do mundo. Pode-se atribuir a esse desenvolvimento a influência dos conceitos e movimento de Humanização em hospitais, da valorização da filantropia, da participação popular e do trabalho das Organizações Não Governamentais (ONGs) em diferentes âmbitos da sociedade civil ${ }^{8}$.

Um aspecto importante da recuperação física do paciente está relacionado à energia utilizada para lidar emocionalmente com a doença e com a internação. Essas condições de crise determinam um elevado grau de elaboração. Inclusive, geram ansiedades e medos em relação ao desenvolvimento dos fatos, além do medo da morte. Nesse contexto, o humor aparece como um recurso importante. Ele permite que a pessoa possa explorar fatos que, por dificuldades pessoais, não poderiam revelar-se de forma aberta e consciente. Tal acesso permite a liberação da energia investida no problema, que, então, pode ser transferida para outros pontos importantes da recuperação do paciente ${ }^{9}$.

A liberdade em criar um aspecto lúdico é um fator importante sobre os trabalhos voluntários de palhaços em hospitais; suas interações estão relacionadas a propostas de jogos e brincadeiras adequados à idade do paciente e ao processo comunicativo.

Há fatores de sucesso no trabalho dos palhaços em hospitais, sendo que o mais evidente é a utilização do humor e da brincadeira como recurso e linguagem de contato. Além disso, eles são capazes de estabelecer uma boa comunicação e contam com um sistema de que cada um possui suas crenças e valores no ambiente hospitalar. A organização, para um palhaço, é aceitar o resultado que se apresenta sem julgamento de valores, mas com desfecho possível ${ }^{7}$.

O sorriso é um indicador de saúde muito importante para o ambiente hospitalar; ele sinaliza que paciente e palhaço 
percorreram uma situação de dificuldade e conseguiram ultrapassar, capazes de transformá-la, ao gerar um vínculo e outra percepção sobre os fatos. O sorriso é um indício de que a vida é capaz de ser vivida em um ambiente diferenciado e vulnerável; é um fator de recuperação, porque leva ao aumento de potência e a uma conduta ativa quanto a uma situação vivenciada, causando bem-estar e melhor interação com o ambiente como um todo ${ }^{7}$.

Os "Doutoralhaços" são um grupo de voluntários que se vestem de palhaços, fundado em 2015, com o objetivo de levar alegria, sorrisos, atenção e humanização para hospitais, abrigos e casas de repouso. Seu público-alvo atinge todas as idades, não fazendo distinção de classe social, econômica, religião ou qualquer tipo de identidade pré-estabelecida.

Este estudo teve como finalidade reforçar a importância do trabalho voluntário em saúde, como instrumento de humanização e de aumento do vínculo estabelecido entre a equipe de profissionais e o paciente, além de averiguar a influência do trabalho do Palhaço ("Clown") como intervenção em saúde, por meio da avaliação da percepção dos integrantes de um grupo inspirado na filosofia dos Doutores da Alegria, os "Doutoralhaços". Os objetivos do estudo foram descrever a percepção dos participantes desse grupo, referentes ao trabalho do Clown - Palhaço como intervenção na saúde, as vantagens, as dificuldades, as facilidades, percebidas, junto aos profissionais da saúde, aos pacientes, aos familiares/ acompanhantes das instituições visitadas, além de valorar a satisfação dos participantes do grupo em relação ao trabalho desenvolvido.

\section{MÉTODOS}

Este estudo consiste em uma investigação qualitativa, de campo com análise de conteúdo dos voluntários do grupo "Doutoralhaços", grupo voluntário paulista que trabalha com Clowns-palhaços, como medida de intervenção na humanização da saúde, em um hospital de grande porte da cidade de São Paulo, em uma unidade clínica médico-cirúrgica de adultos.

Participaram da pesquisa 13 respondentes, que aceitaram voluntariamente o convite, sendo todos membros do grupo "Doutoralhaços", constituindo 56,5\% de todo o grupo que era de 23 pessoas, as quais, voluntariamente, aceitaram participar, conforme Termo de Consentimento Livre e Esclarecido aplicado; por se tratar de pesquisa qualitativa, não há amostra estatística pré-estabelecida.

Foi aplicado um instrumento com duas partes, uma com dados sociodemográficos que incluía idade, sexo, escolaridade, profissão e tempo de grupo nos "Doutoralhaços", e outra, com questionário de perguntas abertas, estruturadas para avaliação da percepção dos voluntários do grupo relativa a: vantagens em saúde que ele antecipa que os pacientes possam ter com o grupo; quais as dificuldades e facilidades percebidas para atuação do grupo junto aos profissionais de saúde, pacientes e familiares/acompanhantes; e uma pergunta tipo likert de 0 a 10 , para avaliar qual o grau de satisfação pessoal com o trabalho voluntário por meio do grupo "Doutoralhaços".

As categorias das análises de conteúdo foram organizadas em uma matriz, em que foram avaliados: Tema, Categoria, Subcategoria e Unidades de Contexto. As respostas ao questionário foram categorizadas por meio da análise de conteúdo, proposta por Bardin (10), relativas a um conjunto de técnicas de análise das comunicações, que utiliza procedimentos sistemáticos e objetivos de descrição do conteúdo das mensagens, agrupadas e distribuídas percentualmente. O estudo foi submetido em 27/9/2015 à avaliação do Comitê de Ética em Pesquisa (CEP) da Universidade Paulista UNIP, de acordo com a legislação vigente 466/12, cujo número de aprovação é: CAAE: 49353015.7.0000.5513.

\section{RESULTADOS}

As características sociodemográficas da amostra foram as seguintes: $61,5 \%$ da faixa etária ficaram entre 18 e 28 anos, com média de idade de 29 anos, relativa à escolaridade 69,2\% com ensino superior completo e $30,8 \%$ incompleto, sendo $76,9 \%$ com até seis meses de tempo de trabalho voluntário dedicado ao grupo "Doutoralhaços". Relativamente ao nível de satisfação dos participantes em relação ao grupo "Os Doutoralhaços", foi satisfatória em 100\% sendo, 2: Satisfatório (nota 9) e 11 Muito Satisfatório (nota 10). Quanto à profissão, havia três advogados e dois estudantes, sendo que os demais trabalhavam em cargos administrativos, com nenhum relacionado à saúde (Tabela1).

Tabela 1. Característocas dos repondentes do estudo "Clown - o palhaço como interevenção em saúde. São Paulo, 2015.

\begin{tabular}{lrr}
\hline Idade & $\mathbf{n}$ & $\mathbf{f p}$ \\
\hline 18 a 28 anos & 8 & 61,5 \\
29 a 39 anos & 4 & 30,8 \\
40 a 50 anos & 1 & 7,7 \\
Total & 13 & 100,0 \\
Escolaridade & & \\
Superior Incompleto & 4 & 30,8 \\
Superior Completo & 9 & 69,2 \\
Total & 13 & 100,0 \\
Tempo de trabalho no grupo de & & \\
"Doutoralhaços" & & \\
01 a 06 meses & 10 & 76,9 \\
07 a 12 meses & 3 & 23,1 \\
Total & 13 & 100,0 \\
Satisfação quanto a participação no grupo & & \\
Muito Satisfeito (nota 10) & 11 & 84,6 \\
Satisfeito (nota 09) & 2 & 15,4 \\
\hline Total & 13 & 100,0 \\
\hline
\end{tabular}


As mensagens nos discursos foram analisadas conforme seu conteúdo e agrupadas em 14 temas, 14 categorias e 32 subcategorias, aqui apresentadas percentualmente, proporcional à quantidade de unidades de conteúdos encontradas em cada uma das subcategorias, aqui evidenciadas com alguns exemplos.

Em relação à categoria "Vantagens de saúde percebidas pelos participantes do grupo", emergiram as subcategorias a "Humanização do Espaço Hospitalar" 9,5\%, a "Boa integração e envolvimento" $14 \%$, a "Melhora da resposta ao tratamento" 33,3\% e destacadamente a "Promoção da Espiritualidade e/ ou apoio Psicológico" 42,9\%, com exemplos de unidades de contexto:

"Autoestima de volta ao paciente, alegria de volta ao paciente, esquecendo, porém momentaneamente a situação em que se encontra"

"Com o ânimo revigorado, eles conseguem encontrar mais forças para se recuperar"

"Melhora da autoestima...supressão da carência de alguns pacientes que ficam sozinhos sem acompanhantes"

Em contrapartida, em relação às "Dificuldades para atuação do grupo junto aos profissionais de saúde", emergiram, com destaque a categoria a "Boa Aceitação e receptividade, sem dificuldades" $61,5 \%$ e a "Aceitação e receptividade com alguma restrição" 38,5\%, com exemplos de unidades de contexto:

"Alguns profissionais, devido ao alto nível de estresse, acabam não nos recebendo positivamente algumas vezes, porém, são raras as vezes que isto acontece, pois, na maioria eles aprovam nossa presença no ambiente hospitalar" "Às vezes, os profissionais não estão de bom humor não querem bagunça e tratam Os Doutoralhaços com frieza"

No tocante às "Dificuldades para a atuação do grupo junto aos pacientes", emergiram a "Boa Aceitação e receptividade, sem dificuldades" 15,4\%, e "Aceitação e receptividade com alguma restrição" 84,6\%"; já em relação às "Dificuldades para a atuação do grupo junto aos familiares/ acompanhantes" há um resultado equilibrado com "Boa Aceitação e receptividade, sem dificuldades" 54\% e "Aceitação e receptividade com alguma restrição" 46\%.

As facilidades de atuação do grupo foram elencadas e apresentaram resultados muito satisfatórios, sendo que, em relação às "Facilidades para a atuação do grupo junto aos profissionais de saúde" emergiram: "Boa integração e envolvimento" 66,7\%, "Reconhecimento do grupo" 27,8\% e "Necessidade de atenção"5,5\%. Em relação às "Facilidades para a atuação do grupo junto aos pacientes" emergiram: "Possibilitar boa integração e envolvimento" 53\% e "Trazer alegria e humanização" 47\%. Já em relação às "Facilidades para a atuação do grupo junto aos familiares/ acompanhantes" emergiram: "Possibilitar alegria e humanização" 64,7\%, "Reconhecimento do grupo" 23,5\% e "Necessidade de atenção" $11,8 \%$.

A "Promoção da Espiritualidade e/ou apoio Psicológico" com
$42,9 \%$, foi a subcategoria que mais se destacou na categoria: "Vantagens em saúde que ele antecipa que os pacientes possam ter com o grupo", seguidos pela "Melhora da resposta ao tratamento" 33,3\%, "Boa integração e envolvimento" $14 \%$ e "Humanização do Espaço Hospitalar" 9,5\%.

As dificuldades para a atuação do grupo são minimizadas com resultados favoráveis, o que fortalece as subcategorias encontradas nas vantagens, descritas categoria anterior, assim em relação às "Dificuldades para a atuação do grupo junto aos profissionais de saúde" emergiram: a "Boa Aceitação e receptividade, sem dificuldades" $61,5 \%$ e a "Aceitação e receptividade com alguma restrição" 38,5\% e Em relação às "Dificuldades para a atuação do grupo junto aos pacientes" destaca-se: a "Aceitação e receptividade com alguma restrição" 84,6\%; e a "Boa Aceitação e receptividade, sem dificuldades" $15,4 \%$, com exemplos de unidades de contexto:

Com dores costumam reclamar...mas logo sorriem e interagem"

"Algumas vezes, alguns pacientes não estão dispostos a receber visitas, mas que é contornado sem dificuldade pelos Doutoralhaços"

"Raras são as vezes que recusam nossa presença...com muita dor... Nesses casos, sempre respeitamos o momento do paciente e dos acompanhantes"

Basicamente, as dificuldades de atuação do grupo junto aos familiares e ou acompanhantes, e aos profissionais de saúde, também parecem ser minimizadas quanto às facilidades, pois, em relação à categoria, "Dificuldades para atuação do grupo junto aos familiares/ acompanhantes", emergiram as subcategorias "Boa Aceitação e receptividade, sem dificuldades" $54 \%$ e a "Aceitação e receptividade com alguma restrição" 46\%, com exemplos de unidades de contexto:

"Alguns acompanhantes e familiares, por estarem nessa situação com o paciente, não tratam Os Doutoralhaços bem, querem descansar e não deixam fazer visita nos pacientes" "Não é sempre que o paciente e seus acompanhantes estão dispostos a nos receber, por motivos particulares ou por não conhecer o projeto"

Em relação à categoria "Facilidades para atuação do grupo junto aos profissionais de saúde", emergiram as subcategorias "Boa integração e envolvimento" 66,7\%, "Reconhecimento do grupo" 27,8\% e "Necessidade de atenção: 5,5\%", com exemplos de unidades de contexto:

"Há muita facilidade e interação..."

"Sempre nos indicam quais pacientes necessitam de uma atenção maior"

"São muito gentis, atenciosos, sempre nos recebem muito bem, nos orientam...vários interagirem com o grupo e tornar a nossa visita mais fácil e gostosa. “

As facilidades de atuação do grupo se apresentaram em duas categorias "Junto aos pacientes" e "Junto aos familiares e ou acompanhantes", e delas emergiram em duas e três subcategorias respectivamente, "Trazer alegria e humanização" 47\%, "Possibilitar boa integração e envolvimento" 53\%; 
"Possibilitar alegria e humanização", 64,7\%, "Reconhecimento do grupo" 23,5\% e "Necessidade de Atenção" 11,8\%, com exemplos de unidades de contexto:

\footnotetext{
"Um evento inesperado que os leva para um momento presente, único. De alegrias, interatividade, risos, enfim, é uma conexão humana que nem todos ali estão esperando" "Às vezes, ele só quer conversar e, às vezes, só quer um abraço ou aperto de mão"

"Nessa hora, esquecem-se de seu estado e entram em nossa brincadeira."

"Os familiares e acompanhantes em geral nos recebem muito bem, por sentir que queremos levar alívio para seus entes queridos"
}

\section{DISCUSSÃO}

O grupo apresentou características de uma nova geração que está preocupada em realizar trabalhos voluntários fora de seu escopo de trabalho diário; um grupo jovem, com nível universitário, sem experiências em saúde, mas que demonstrou muita satisfação na realização do trabalho de intervenção e humanização do espaço hospitalar por meio da atividade do Clown.

A importância com a humanização se torna cada vez mais presente, e o número de voluntários dispostos a prestar esse tipo de serviço tem aumentado nas diferentes áreas da sociedade, inclusive, em hospitais, por se tratar de um ambiente em que os pacientes se sentem desconfortáveis em meio ao quadro de vulnerabilidade em que eles se encontram ${ }^{11}$.

A percepção que os participantes têm em relação à resposta do tratamento é vista de forma clara nesses discursos e em tantos outros presentes na matriz de análise de conteúdo, o que destaca uma comprovação de um trecho do livro Boas Misturas de Massetti7: "O sorriso é um indicador de saúde muito importante para o ambiente hospitalar. "

Com base neste contexto em comparação com a autora, salienta-se a importância de que existe uma melhora no estado de ânimo do paciente, e ela está totalmente relacionada a uma melhora de seu quadro clínico ao se considerar que esse paciente é um ser biopsicossocial.

A principal percepção de vantagem apontada pelo grupo relativa foi a "Promoção da Espiritualidade e/ou apoio Psicológico" (42,9\%). Os participantes, com base em suas percepções, reconheceram a importância de salientar a parte psicológica do paciente não só quando ele se depara apenas com a doença, mas quando enfatiza o olhar amplo de sua existência, o que é fundamental para a melhora da saúde do paciente segundo Backes $^{1}$ :

\footnotetext{
"Sendo que a humanização do cuidado ao paciente compreende, antes de tudo, uma relação efetiva de cuidado, que pode se evidenciar na acolhida, na sensibilidade, no respeito e na compreensão do doente e não somente da doença".
}

Fica evidente que a visão do ser humano e de suas necessidades está-se ampliando; é preciso negar o reducionismo que foi imposto à humanidade, com foco nas relações físicas e de doença, para uma abordagem holística e de abrangência social, psicológica e espiritual, como fatores somatórios de promoção e recuperação da saúde e bem-estar. Importante ressaltar que, embora haja percepção da possibilidade da promoção, inclusive do bem-estar espiritual, essa atividade não é de fácil execução, segundo Conceição ${ }^{12}$ :

\begin{abstract}
"Precisamos de saber o que são cuidados espirituais e de os aplicar na nossa vida, este é o grande desafio, colocado, hoje, àqueles que, nas mãos, trazemos muitas vezes a possibilidade de ajudar pessoas que vivem vidas sem esperança a encontrar novo sentido e perspectivas diferentes alargando assim os seus horizontes existenciais".
\end{abstract}

Relativo às dificuldades para atuação do grupo junto aos profissionais de saúde, nota-se que a maioria, 61,5\%, percebeu não ter dificuldades de atuação relacionada aos profissionais de saúde, o que aponta para uma boa receptividade dos profissionais e para o fato de que eles sabem da importância da humanização hospitalar presente no trabalho voluntário. 0 mesmo resultado foi percebido e apontado pelos colaboradores em relação à mudança do ambiente da assistência em estudo realizado com idosos utilizando o Clown como intervenção na depressão ${ }^{13}$.

Ficou evidente que o eventual motivo da restrição dos profissionais é exatamente o nível de estresse causado pelo ambiente hospitalar. Esse fato faz pensar que a humanização não deve ser voltada apenas ao paciente, mas em todo ambiente hospitalar, inclusive nos próprios profissionais, a fim de manter uma assistência ampla e eficaz, pois, se o profissional de saúde é humanizado, ele replicará esta filosofia com todos à sua volta, equipe multidisciplinares e pacientes e acompanhantes. Segundo Araújo et. al. ${ }^{14}$, em estudo realizado com atividades lúdicas em ambiente hospitalar pediátrico, para além dos benefícios aos pacientes, "o serviço de saúde prestado nessa enfermaria pediátrica também era beneficiado com a realização dessas atividades que humanizavam e acolhiam os pacientes ali internados". Esse discurso aparece com sugestão de a visita também ter um foco nos profissionais em uma das frases dos participantes:

“(...) seria importante a disponibilidade de tais profissionais para acompanhar e participar das visitas"

Contrariamente à facilidade com a equipe, chamaram à atenção as dificuldades para a atuação do grupo junto aos pacientes, sendo relatada dificuldade com aceitação e receptividade, com alguma restrição em $84,6 \%$. Nota-se que, na minoria das vezes, a visita torna-se sem dificuldades alguma, pois, em se tratando de um hospital, o trabalho voluntário tem certa barreira em relação ao conforto do paciente. Porém, como salientado pelos participantes, esta restrição está apenas no começo da visita. Depois que percebem o intuito do projeto, os pacientes acabam-se descontraindo e sendo mais receptivos. 
É importante reforçar a importância do preparo que se tem que ter em relação à recusa dos pacientes, pois os participantes, não sendo profissionais da saúde, às vezes, sentem-se despreparados para esta ocasião, não sabendo lidar com a dor do paciente ${ }^{12}$, tendo a necessidade de se ter um curso ou treinamento preparatório para a ocasião como citado por um membro do grupo "Doutoralhaços":

“ $\mathrm{Na}$ verdade, todos os voluntários precisam ter a sensibilidade de saber quando o paciente está disposto a receber a visita"

Já nas dificuldades para a atuação junto aos familiares e/ ou acompanhantes, também há uma boa aprovação, $54 \%$, a maioria sem dificuldades diante deles. O que chama a atenção é o motivo das restrições, curiosamente as barreiras apontadas são as mesmas ou parecidas, encontradas junto aos profissionais de saúde, anteriormente discutidas, sendo elas o estresse e o cansaço físico e/ou emocional causado pelo ambiente hospitalar.

Novamente, deve-se abordar a questão de que a humanização no espaço hospitalar deve ser ampliada, direcionada não só ao paciente, mas aos profissionais de saúde e aos familiares e ou acompanhantes, pois o ambiente humanizado provoca um cuidado diferenciado e tão necessário para o paciente que está em condição debilitada, tornando-o mais receptivo aos cuidados e tratamentos. Destaca-se, então, mais uma vez, a necessidade de o trabalho voluntário se preparar para a extensão da abordagem humanizada.

Em relação às facilidades percebidas junto aos profissionais de saúde, o reconhecimento do grupo é bastante presente; parece compreender a filosofia da humanização do ambiente hospitalar, que deve estar presente no contexto de todas as profissões de saúde.

Com base no relato dos participantes, os próprios profissionais de saúde, por meio de sua vivência, têm essa percepção de saber que o estado de ânimo do paciente interfere, sim, em seu bem-estar físico, mental e social. Na ótica de Fortes ${ }^{15}$, ele interpreta que humanizar na atenção à saúde é compreender cada indivíduo em sua singularidade, tendo necessidades peculiares, e, assim, criando condições para que tenha maiores possibilidades para exercer sua vontade de forma autônoma. Nesse sentido, pode-se abranger uma definição de que o paciente é um ser biopsicossocial e espiritual ${ }^{12}$.

Para tal, deve-se compreender que, para humanizar, é preciso ser humanizado, no sentido de compreender e praticar a humanização em todo contexto, assim como se vê em uma das respostas:

"Vejo que algumas vezes também necessitam de certa atenção assim como pacientes e acompanhantes"

Volta-se à discussão de se humanizar todo o contexto hospitalar, como diz a Política Nacional de Humanização na Assistência
Hospitalar, no Brasil. O objetivo do PNHAH seria o de aprimorar as relações entre profissionais, entre paciente e profissional e entre hospital e comunidade, visando à melhoria da qualidade e à eficácia dos serviços prestados por estas instituições².

Com base nesse contexto, há a questão abordada em $66,7 \%$ dos participantes, que é a "Boa integração e envolvimento", sempre presente com frases e palavras como "auxílio e orientações", o que deixa clara a importância de ter uma boa interação e comunicação com os profissionais da saúde, sendo um ponto extremamente positivo encontrado pelos participantes, pois, para humanizar, é preciso encontrar formas de se comunicar com a equipe e com os pacientes. Deve-se enfatizar a ideia de que o primeiro elo com o paciente e os voluntários Clown é a equipe multiprofissional ${ }^{13}$. Então, se houver maneiras de se sustentar esta parceria para aprimorar a visita, como um meio de tornar mais fácil a receptividade do paciente/acompanhante, melhor será o aproveitamento da visita conforme relatado.

Portanto, tendo como base Rockenback ${ }^{16}$, pode-se compreender que a equipe de profissionais de saúde, antes de atuar junto ao paciente, precisa estar integrada como grupo de pessoas, cujo objetivo é comum: o bem-estar do paciente, que deve, dentro do menor prazo possível, ser capaz de voltar a realizar seu autocuidado.

Em relação às facilidades para a atuação do grupo junto aos pacientes, aparece "Trazer alegria e humanização" em 47\% dos discursos e "Possibilitar boa integração e envolvimento" em 53\%. A facilidade de atuação em relação aos pacientes está totalmente ligada aos discursos em que os participantes enfatizaram terem sido bem recebidos com alegria a partir do momento em que surge o inesperado. A surpresa é concedida por meio da alegria em um contexto invertido, pelo fato de a demagogia se prender ao fato de o ambiente hospitalar ser caracterizado negativamente pelo fator doença. Esta surpresa foge da regra negativa, fazendo que o paciente torne a repensar um mundo mais dinâmico e interativo, enxergando o próprio lado humano e intrínseco, esquecendo o estresse da doença que diminui seu estado de ânimo, tornando possível sua maior receptividade e integração com o grupo ${ }^{7}$ também relatado pelo grupo:

"Ficam muito emocionados com a nossa presença... não imaginavam que naquele quadro iriam ter alegria e felicidade"

"Os Doutoralhaços têm muita facilidade de interação, acredito que, com a vontade de levar alegria aos pacientes, a visita fica cada vez mais fácil e agradável."

Em relação às facilidades para a atuação do grupo junto aos familiares/ acompanhantes, $64,7 \%$ se referem a "Possibilitar alegria e humanização". Desse modo, pode-se afirmar que os familiares/acompanhantes têm esta questão bem definida em relação ao que é um trabalho humanizado. Com base nisto, abrem-se grandes possibilidades na composição de melhora do estado de ânimo, ou seja, se o acompanhante passa essa confiança ao grupo, automaticamente, o paciente sente esta confiança e acaba tendo maior receptividade para interagir, o 
que mostra o quanto é importante o reconhecimento do grupo perante esses acompanhantes.

Vale ressaltar que $11,8 \%$ dos participantes relataram a necessidade de atenção da humanização para os familiares também, voltando sempre ao âmbito de se humanizar o ambiente como um todo, pois, se o acompanhante tem esta sensibilidade de lidar com o lúdico, o brincar, ele repassa isso ao paciente, esquecendo o estresse da dor e da doença (1314) . Logo, ambos se sentem importantes dentro do contexto; trata-se, então, de se ver o lado humano como um todo, não tendo foco em apenas um objetivo, mas sim, tendo uma visão ampla das necessidades biopsicossociais e espirituais de cada indivíduo, mesmo que se humanize o grupo, os profissionais, os acompanhantes, os pacientes, enfim, o ambiente por um todo. Portanto, o estudo mostrou a importância do trabalho voluntário dos "Doutoralhaços" com a humanização na intervenção em saúde.

Um projeto chamado "Uma canção no Cuidar em Unidade de Internação", realizado pelo grupo de voluntários do "Menestréis", que foi um grupo de profissionais da saúde que cantavam e tocavam para os pacientes do hospital de Samaritano de São Paulo, teve seus potenciais benefícios citados no livro "Cuidar de pessoas e música: uma visão multiprofissional" da autora Eliseth Ribeiro Leão ${ }^{15}$, pesquisadora que também fazia parte deste grupo e que teve como objetivo proporcionar parâmetros-alvo de qualidade para a reflexão e a utilização da música. A abordagem de interação musical, segundo a autora, acabou por aproximar mais o grupo dos participantes, fossem eles pacientes, acompanhantes ou familiares, permitindo ainda a entrada nos quartos quando um paciente estava acamado, e os familiares ou a enfermagem os solicitavam. Esse caráter mais dinâmico, ainda que, segundo a autora, prejudique um pouco a abordagem cognitivo-comportamental, tem-se mostrado mais espontâneo, facilitando, também, a comunicação não verbal mediada, no caso deste grupo, pela música ${ }^{17}$.

Pode-se notar um bom exemplo citado pela autora de humanização em todo e qualquer tipo de voluntariado, desde que este seja feito de forma comprometida com os valores éticos e sociais advindos de suas ações com os pacientes. É notável a intenção de levar bem-estar àqueles que estão em uma situação delicada tendo em vista o ambiente propício a enfermidades, como é o hospital. Baseado neste contexto, pode-se afirmar a suma importância que tem a ação voluntária em caráter geral na humanização, promoção à saúde e desenvolvimento humano.

A maior dificuldade ou limitação desta investigação concentrouse em ser um estudo qualitativo, não generalizável; no entanto, os resultados aqui apresentados vão ao encontro de recente publicação de Finlay et. al. (180 , em que se observa que a avaliação rigorosa da terapêutica dos efeitos do "clowning", com é chamada, internacionalmente, a intervenção com o Clown, é complexa, como o modelo multimodal de intervenção, que pode ter impacto nas condições médicas, procedimentos, funcionamento familiar e de equipes de saúde, sendo que a base fisiológica do "clowning" está só no início da exploração, com respostas mais específicas sobre o aumento da imunidade, melhora da resiliência e redução do estresse, aliviando a dor e liberando endorfinas. É certo que os palhaços fazem crianças e adultos rirem, e o Clown, como intervenção, está sendo introduzido nos cuidados em saúde para pacientes pediátricos e adultos com demências ou psicoses e até para a fertilização in vitro.

\section{CONCLUSÃO}

Foi possível concluir que a humanização é ponto chave do bemestar do paciente, pois permite olhá-lo de forma holística, integralmente, como um ser biopsicossocial e espiritual, e não tão somente com um olhar na doença em si.

Por meio da percepção dos participantes, foi possível afirmar que não se deve ter somente o foco no paciente, mas em todo o contexto hospitalar, ou seja, estender as ações de humanização aos profissionais de saúde e aos familiares e/ou acompanhantes dos pacientes, também estes sendo olhados holisticamente em seu ser biopsicossocial e espiritual.

O trabalho do voluntário por meio do Clown, neste estudo, apontou que as maiores facilidades se concentraram na tratativa com os pacientes, que demonstram sentir-se bem com a visita dos voluntários Clown. Eles relatam perceber melhora ou algum alívio no estresse relativo à doença e/ou internação, que, normalmente, acaba causando uma piora no quadro do paciente. Já em relação às dificuldades percebidas, a maioria estava relacionada ao quadro de dor ou de estresse encontrado, tantos nos pacientes, como, também, nos profissionais de saúde e familiares e/ou a acompanhantes, fortalecendo percepção de que todos precisam de atenção na prática de humanização do ambiente hospitalar.

Ficou clara a grande satisfação pessoal que o trabalho voluntário como Clown, aqui como "Doutoralhaços", proporciona a todos os participantes, incluindo a satisfação do reconhecimento desse trabalho relatada por meio das relações com os profissionais de saúde e com familiares e/ou acompanhantes.

A intervenção de saúde do trabalho do Clown é factível no ambiente hospitalar à medida que humaniza, estimula a recuperação do ser humano de forma ampla, conforme relatou uma paciente no projeto "Uma Canção no Cuidar", da Dra. Eliseth Leão: "todo sofrimento merece um recreio" $" 17$.

\section{AGRADECIMENTOS}

Agradecemos aos Doutoralhaços por aceitarem participar desta pesquisa tão importante para o trabalho voluntário. Sem eles, esta pesquisa não aconteceria. 


\section{REFERÊNCIAS}

1. Backes DS, Lunardi WD Filho; Lunardi VL. Humanização hospitalar: percepção dos pacientes. Acta Sci. Health Sci. 2005; 27(2): 103-107.

2. Ministério da Saúde (BR), Secretaria de Assistência à Saúde. Programa Nacional de Humanização da Assistência Hospitalar. Brasília; 2001. 60p.

3. Ministério da Saúde (BR), Secretaria Executiva, Núcleo Técnico de Política Nacional de Hmanização, Humaniza SUS: política nacional de humanização: a humanização como eixo norteador das práticas de atenção e gestão em todas as instâncias do SUS. Brasília; 2004. 20p.

4. Nogueira-Martins MCF, Berusa AAS. Siqueira SR. Humanização e voluntariado: estudo qualitativo em hospitais públicos. Rev Saúde Pública. 2010 Oct; 44(5): 942-9. doi: http://dx.doi.org/10.1590/S0034-89102010005000032.

5. Machado MMP, Goia-Martins D. A criança hospitalizada: espaço potencial e o palhaço. Boletim de Iniciação Científica em Psicologia. 2002; 3(1): 34-52.

6. sobre os doutores da alegria: 25 anos de atuação no Brasil [Internet]. 2017 [acesso 201 Ago 15]. Disponível em: http://www.doutoresdaalegria.org.br/ conheca/sobre-os-doutores/.

7. Masetti M. Boas Misturas: a ética da alegria no contexto hospitalar. São Paulo: Palas Athena; 2003.

8. Masetti M. Boas misturas: possibilidades de modificações da prática do profissional de saúde a partir do contato com os Doutores da Alegria [dissertação]. São Paulo (SP): PUC; 2001.

9. Masetti M; Soluções de palhaços: transformações na realidade hospitalar. São Paulo: Palas Athena; 1998.

10. Bardin L. Análise de conteúdo. Lisboa: Edições 70; 2011.
11. Moniz ALF; Araújo TCCF. Voluntariado hospitalar: um estudo sobre a percepção dos profissionais de saúde. Estudos de Psicologia [Internet]. 2008 [acesso 2015 Ago 16]; 13(2): 149-156. Disponível em: www.scielo.br/epsic.

12. Conceição AP. A competência para o cuidado espiritual em enfermagem. Loures: Lusodidacta; 2015.

13. Pires WGP, Pessalacia JDR, Mata LRF, Kuznier TP, Panitz GEC. Efeito da Intervenção Clown no Padrão de depressão de idosos em instituição de longa permanência. Ciencia y Enfermeria. 2015; 21(2): 99-111.

14. Araújo RAS, Silva FA, Faro A, Sobral ALO. Uso de atividades lúdicas no processo de humanização em ambiente hospitalar pediátrico: intervenção Programa de Educação pelo Trabalho para a Saúde (PET/Saúde REDES Urgência e Emergência). Rev. SBPH [Internet]. 2016 Dez [acesso 2017 Jun 11]; 19( 2 ): 98-106. Disponível em: http://pepsic.bvsalud.org/scielo.php?script=sci arttext\&pid=S1516-08582016000200007\&lng=pt.

15. Fortes PAC. Ética, direitos dos usuários e políticas de humanização da atenção à saúde; Saúde soc. 2004 Set-Dez; 13(3): 30-35. doi: http://dx.doi. org/10.1590/S0104-12902004000300004.

16. Rockenbach L H. A enfermagem e a humanização do paciente. Rev. bras. enf. 1985 Jan-Mar; 38(1): 49-54. doi: http://dx.doi.org/10.1590/S003471671985000100007.

17. Leão E.R, organizadora. cuidar de pessoas e música: uma visão multiprofissional. São Caetano do Sul: Yendis; 2009. p-324-326.

18. Finlay F, Baverstock A, Lenton S. Therapeutic clowning in hospital settings: more than a play-fool proposal. Arch Dis Child. 2017 Jul; 102(7): 597-598. doi: 10.1136/archdischild-2017-312715. PubMed PMID: 28465302.

\section{Como citar este artigo/How to cite this article:}

